DOI: https://doi.org/10.24867/06BE07Knezevic

\title{
ULAZNI STEPEN EDUKATIVNOG ELEKTROFIZIOLOŠKOG AKVIZICIONOG UREDAJA
}

\section{FRONTEND OF AN EDUCATIONAL ELECTROPHYSIOLOGICAL ACQUISITION DEVICE}

\author{
Boris Knežević, Fakultet tehničkih nauka, Novi Sad
}

\section{Oblast - ELEKTROTEHNIKA I RAČUNARSTVO}

Kratak sadržaj - Rad predstavlja realizaciju edukativnog elektrofiziološkog akvizicionog uređaja pomoću Mikromedia for Xmega razvojnog okruženja $i$ akvizicionog modula baziranog na ADS1299 integrisanom kolu. U radu su detaljno opisane komponente sistema, kao i programski kod. Na kraju rada dati su rezultati i njihova analiza.

Ključne reči: Mikrokontroler, elektrofiziološki signali

Abstract - The paper represents the realization of an educational electrophysiological acquisition device using the Mikromedia for Xmega developing platform and the ADS1299 microchip. It describes the components of the system as well as the program code. The end of the paper displays the results and the analysis of those results.

Keywords: Microcontroller, electrophysiological signal

\section{UVOD}

Biomedicinsko inženjerstvo predstavlja multidisciplinarnu oblast sastavljenu od niza užih naučnih delatnosti. Sa tehničke strane, to su metode obrade signala, elektronika, sistemi automatskog upravljanja, merno-akvizicioni sistemi itd. Sa medicinske strane, to su anatomija, fiziologija, neurologija, histologija itd [1].

Na Fakultetu tehničkih nauka Univerziteta u Novom Sadu realizovan je studijski program Biomedicinsko inženjerstvo koji se upravo bavi izučavanjem prethodno navedenih oblasti. Određeni broj kurseva na ovom studijskom programu se bavi akvizicijom i analizom elektrofizioloških signala.

Zbog tehničke složenosti akvizicionih elektrofizioloških uređaja i standarda koji oni moraju da zadovoljavaju, pre svega u smislu zaštite subjekata nad kojima se ti signali snimaju, studenti koji izučavaju ovaj studijski program veoma teško mogu samostalno da snime elektrofiziološke signale koje bi nakon toga mogli da obrađuju i analiziraju.

Otud je proistekla ideja za realizacijom edukativnog elektrofiziološkog akvizicionog uređaja koji ima zadatak da bolje upozna studente sa ovom granom biomedicinskog inženjerstva $\mathrm{i}$ da im pruži neophodno praktično iskustvo koje će im pomoći u daljem obrazovanju i usavršavanju.

\section{NAPOMENA:}

Ovaj rad proistekao je iz master rada čiji mentor je bio dr Nikola Jorgovanović, red. prof.
U poslednjih nekoliko godina, ova oblast je značajno počela da se razvija i proširuje, pa tako već postoji značajan broj naučnih radova koji se upravo bave analizom $\mathrm{i}$ razvojem elektrofizioloških akvizicionih uređaja koji se primenjuju u edukaciji. Edukativni elektrofiziološki mernoakvizicioni sistem opisan je u radu [3]. Ovaj naučni rad opisuje prototip merno-akvizicionog sistema čiji je osnovni zadatak da reši probleme prenosivosti, lošeg odnosa signalšum, pristupačnosti korisnicima itd. Sistem je, pre svega, služio za akviziciju EKG signala i fotopletizmografiju, a realizovan je primenom mikrofona i zvučne kartice. Za obradu i prikazivanje prikupljenih podataka korišćeno je razvojno okruženje MATLAB.

Merno-akvizicioni uređaj opisan u radu [4] takođe je korišćen u edukativne svrhe. Uređaj je razvijen na Raspberry PI platformi i služio je za merenje EKG signala, a pored toga, implementirano je i merenje impedanse interfejsa elektroda-tkivo. Prikupljeni podaci su se, zatim, slali putem Bluetooth konekcije na PC računar gde se vršila njihova obrada i vizuelizacija.

U naučnom radu [5] opisan je merno-akvizicioni sistem koji je primarno realizovan kako bi ga koristili student $\mathrm{u}$ toku edukacije. Signali su se prikupljali putem senzora, a do PC računara su se slali putem RS232 interfejsa. Za prikazivanje prikupljenih podataka korišćeno je LabVIEW razvojno okruženje.

Pored prethodno navedenih merno-akvizicionih sistema koji najčešće koriste PC računare i aplikacije, postoje i sistemi koji uključuju pametne telefone. Uređaj opisan u radu [6] razvijen je na Raspeberry PI platformi. Prikupljeni podaci su putem wireless komunikacije dalje prosleđeni do mobilnog telefona, gde se vršila vizuelizacija tih podataka. Cilj ovog rada je da prikaže realizaciju edukativnog elektrofiziološkog akvizicionog uređaja primenom Micromedia for Xmega razvojnog sistema razvijenim oko mikrokontrolera ATxmega128A1 i akvizicionog modula baziranog na ADS1299 integrisanom kolu. Uređaj je prenosiv, intuitivan i jednostavan za upotrebu, a namenjen je za snimanje električne aktivnosti srca i mišića. Navedene tri osobine ukazuju na to da je uređaj pogodan upravo za studentsku upotrebu u toku izvođenja laboratorijskih vežbi.

\section{HARDVER}

Hardverski deo uređaja se sastoji iz dva dela: Mikromedia for XMEGA razvojne platforme [7,8] i akvizicionog modula, razvijenog na Fakultetu tehničkih nauka u Novom Sadu, baziranog na ADS1299 integrisanom kolu [9]. Strukturni blok dijagram sistema prikazan je na slici 1 . 


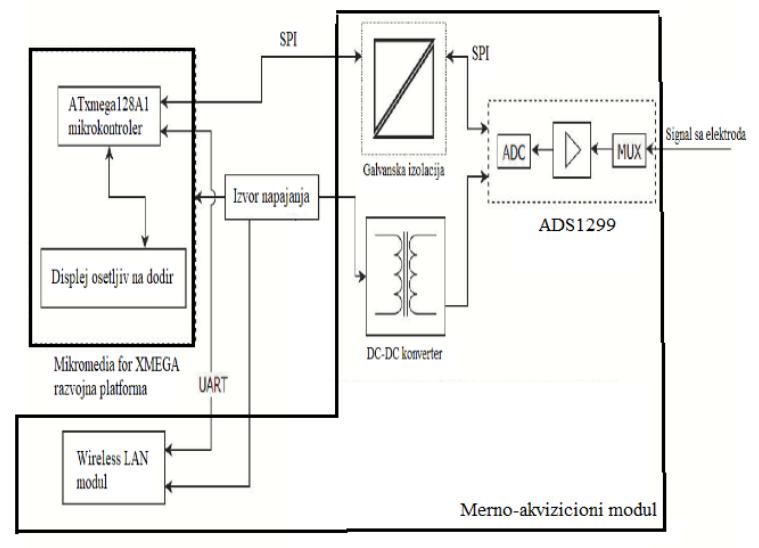

Slika 1. Strukturni blok dijagram sistema

\subsection{Merno-akvizicioni modul}

Centralni deo merno-akvizicionog modula je ADS1299 integrisano kolo. Proizvod je kompanije Texas Instruments i najčešće se koristi za snimanje električne aktivnosti kore velikog mozga (elektroencefalogram, tj. EEG signal) i električne aktivnosti srca (elektrokardiogram, tj. EKG signal). Osnovna uloga ovog modula jeste snimanje i prikupljanje elektrofizioloških signala, obrada i pojačanje tih signala $i$ njihova konverzija iz analognog $u$ digitalni oblik. U pitanju je osmokanalni modul koji sadrži osam diferencijalnih ulaza sa implementiranim antialiasing filtrom, osam 24-bitnih delta-sigma $(\Delta \Sigma)$ analogno-digitalnih konvertora i osam pojačavača sa promenljivom vrednošću pojačanja (Programmable Gain Amplifier, $P G A$ ). Pored toga, modul sadrži i multiplekser, interni generator test signala, interni oscilator, DRL (Driven Right Leg) kolo i SPI (Serial Peripheral Interface) modul za komunikaciju sa drugim uređajima. Pored ADS1299 merno-akvizicioni modul sadrži još i modul za napajanje i galvansko razdvajanje, interfejs za pulsni oksimetar i WiFi komunikacioni modul.

\subsection{Mikromedia for XMEGA}

Mikromedia for XMEGA razvojna platforma proizvod je kompanije MikroElektronika i predstavlja najvažniju hardversku komponentu ovog sistema. Ova razvojna pločica sadrži sve neophodne resurse neophodne za pravilnu akviziciju elektrofizioloških signala. Centralni deo razvojne pločice čini 8-bitni mikrokontroler Atxmega128A1. Osnovni zadatak ovog mikrokontrolera je da reguliše procese akvizicije, obrade i vizuelizacije signala.

Kao što je već napomenuto, osnovna komponenta razvojne pločice je mikrokontroler Atxmega128A1. U pitanju je mikrokontroler iz AVR familije mikrokontrolera koji sadrži 8-bitni mikroprocesor RISC (Reduced Instruction Set Computer) arhitekture i 100 ulazno/izlaznih pinova. Predviđen napon napajanja se kreće u granicama između $1,6 \mathrm{~V}$ i 3,6 V. Što se tiče memorije, mikrokontroler poseduje 128 kilobajta programske ili fleš (flash) memorije, 8 kilobajta SRAM (Static Random Access Memory) memorije i 2048 bajtova EEPROM (Electrically Erasable Programmable Read-Only Memory) memorije. Mikrokontroler sadrži osam 16-bitnih tajmera i brojača, dva 12-bitna A/D konvertora, dva 12-bitna D/A konvertora, kao i modul za serijsku komunikaciju. Frekvencija rada mikroprocesora iznosi $32 \mathrm{MHz}$.

\section{FIRMVER}

Za pisanje firmvera korišćeno je radno okruženje mikroC PRO for AVR, razvijeno od strane kompanije Mikroelektronika. MikroC PRO for AVR je programsko okruženje za programiranje mikrokontrolera u programskom jeziku $C$.

\subsection{Inicijalizacija}

Dovođenjem odgovarajućeg napajanja, mikrokontroler počinje sa radom, nakon čega kreće njegova inicijalizacija. Prva funkcija koja se izvršava je funkcija Init(), koja služi za definisanje vrednosti flegova, koji će imati važnu ulogu u kontrolisanju daljeg toka programa. Flagovi spadaju u promenljive tipa bit i mogu imati dve vrednosti: 1, tj. TRUE i 0, tj. FALSE. Prilikom inicijalizacije, vrednosti svih flegova se postavljaju na FALSE, osim promenljive I_bit čija se vrednost postavlja na TRUE. Promenljiva I_bit kontroliše globalnu dozvolu za izvršavanje prekidnih rutina. Pored $I \_b i t-a$, da bi se omogućilo izvršavanje prekidnih rutina svih prioriteta, potrebno je podesiti poslednja tri bita 8-bitnog PMIC_CTRL registra na 1.

Nakon izvršavanja ove funkcije, kreće inicijalizacija prekidnih rutina koje će se koristiti u toku izvršavanja glavnog programa. Prekidne rutine koje treba inicijalizovati su prekid SPI komunikacije (funkcija SPIInit()) i eksterni prekid na pinu EEG_DRDY (funkcija $D R D$ YInit()).

SPI komunikacioni protokol se koristi za razmenu podataka između ATxmega128A1 mikrokontrolera i ADS1299 integrisanog kola. Mikrokontroler Atxmgea128A1 predstavlja master uređaj, a integrisano kolo ADS1299 predstavlja slave uređaj, što je u kodu definisano podešavanjem SPID_CTRL registra.

Poslednji prekid koji je potrebno inicijalizovati je DRDY eksterni prekid na pinu E6. Eksterni prekid na određenom pinu se definiše postavljanjem 1 na na odgovarajućem bitu PORTE_INTOMASK registra. Mikroprocesor izvršava ovu prekidnu rutinu u trenutku kada je završeno prikupljanje novih podataka sa svih A/D konvertora integrisanog kola ADS1299. Ova prekidna rutina predstavlja osnovu akvizicije podataka, i zbog toga je prioritet ovog prekida postavljen na najviši nivo. To je urađeno postavljanjem 11 na poslednja dva bita registra PORTE_INTCTRL.

\subsection{Akvizicija signala}

Postavljanjem vrednosti EEG_ENABLE i EEG_START pinova na $T R U E$, započinje akvizicija signala. U trenutku kada su prikupljene vrednosti signala na svim kanalima (3 bajta za svaki kanal, ukupno 24 bajta podataka), aktivira se eksterni DRDY prekid na pinu E6. U toj prekidnoj rutini, vrednost flag-a read_data, koji omogućava čitanje prikupljenih podataka, postavlja se na TRUE. Podaci se nakon toga iščitavaju u prekidnoj rutini SPI komunikacije. Prekidna rutina SPI komunikacije započinje iščitavanjem SPID_STATUS i SPID_DATA registara. Prikupljeni podaci nalaze se u SPID_DATA registru. U toku jednog izvršavanja prekidne rutine moguće je iščitati samo jedan bajt podataka. Zbog toga se uvodi brojač read_byte_counter koji sadrži informaciju koliko je bajtova podataka iščitano. Iščitani podaci se smeštaju u niz signal_all_channels i šalju se dalje na obradu. Kada se preuzmu svih 24 bajtova podataka, vrednost flag-a read_data se postavlja na FALSE. Postupak se ciklično ponavlja svaki put kada se prikupi nova 24 bajta podataka. 


\subsection{Obrada podataka}

Nakon akvizicije podataka kreće njihova obrada. Kao što je već rečeno, vrednost signala snimljenog na jednom od 8 kanala opisana je sa 3 bajta koji su smešteni u 3 različite promenljive. Prvi bajt predstavlja najviši bajt u paketu, dok je treći najniži bajt u paketu. Prvi zadatak jeste ta 3 bajta upakovati u jednu 32-bitnu promeljivu tipa long. Prvi korak ovog zadatka predstavlja eksplicitnu konverziju ta tri 8-bitna podatka u tri 32-bitna podatka. Nakon toga, primenjuje se operacija nad bitima poznata kao šiftovanje. Prvi bajt sadrži najznačajnije bite, pa se zbog toga oni pomeraju (šiftuju) za 16 mesta ulevo. Drugi bajt sadrži bite srednje značajnosti, pa se zato oni šiftuju za 8 mesta ulevo, dok treći bajt sadrži najmanje značajne bite, pa zbog toga oni ostaju na pozicijama na kojima se trenutno nalaze. Nakon šiftovanja, tri 32-bitna podatka se spajaju u jednu promenljivu primenom logičke operacije ili $(O R)$.

Dobijena 32-bitna promenljiva predstavlja vrednost signala u komplementu dvojke. Dobijena vrednost je neoznačena (sve vrenosti su pozitivne), i nalazi se u opsegu od 0 do $2^{24}$ - 1 . Ove vrednsti je potrebno konvertovati iz neoznačenog (unsigned) tipa u označeni (signed) tip. Kod reprezentacije brojeva u komplementu dvojke, prvu polovinu vrednosti (od 0 do $2^{23}-1$ ) predstavljaju pozitivni brojevi, dok drugu polovinu vrednosti (od $2^{23}$ do $2^{24}-1$ ) predstavljaju negativni brojevi. Zbog toga, da bi se dobila označena vrednost, neophodno je proveriti da li je je ova dobijena vrednost veća od polovine vrednosti celokupnog opsega. Ukoliko jeste, od vrednosti se oduzima maksimalna vrednosti opsega, tj. $2^{24}$. Ukoliko nije, vrednost ostaje nepromenjena.

Naredni zadatak koji je potrebno obaviti je izvršiti konverziju vrednosti signala iz komplementa dvojke u decimalnu vrednost, tj. $\mathrm{u}$ vrednost $\mathrm{u}$ voltima. To se radi $\mathrm{uz}$ pomoć sledeće formule:

$$
1 L S B=(2 \times V R E F / \text { Gain }) / 2^{\wedge} 24
$$

pri čemu Vref iznosi 4,5 V, a Gain predstavlja pojačanje PGA pojačavača i iznosi 24. Dobijena konvertovana vrednost je izražena u voltima. Iz razloga što elektrofiziološki signali imaju amplitude reda milivolti, čitav izraz je pomnožen sa 1000 .

Opisanom konverzijom dobijeni su odbirci snimanog elektrofiziološkog signala. Pre njegovog iscrtavanja, potrebno ga je filtrirati. Snimljeni signal poseduje pomerenu baznu liniju i određeni visokovrekvencijski šum. Za eliminaciju pomerene bazne linije realizovan je visokopropusni IIR (Infinite Impulse Response) filtar trećeg reda i granične učestanosti $0,5 \mathrm{~Hz}$. Visokofrekventni šum eliminisan je iz signala primenom tehnike usrednjavanja. Usrednjena vrednost se dobija računanjem srednje vrednosti 15 prethodno izračunatih odbiraka signala. Elektrofiziološki signal se nakon svih obrada šalje na iscrtavanje.

\section{REZULTATI}

Proces testiranja rada uređaja podeljen je na dve faze:

1. Snimanje signala sa test generatora,

2. Snimanje elektrofiziološkog signala.

\subsection{Test signal}

Signal dobijen preko internog test generatora predstavlja povorku pravougaonih impulsa amplitude $3,75 \mathrm{mV}$ i periode od $0,97 \mathrm{~s}$. Na slici 2 prikazan je snimljeni signal na vremensom intervalu od 0 do 5 sekundi i amplitudskom rezolucijom od $+/-5 \mathrm{mV}$.

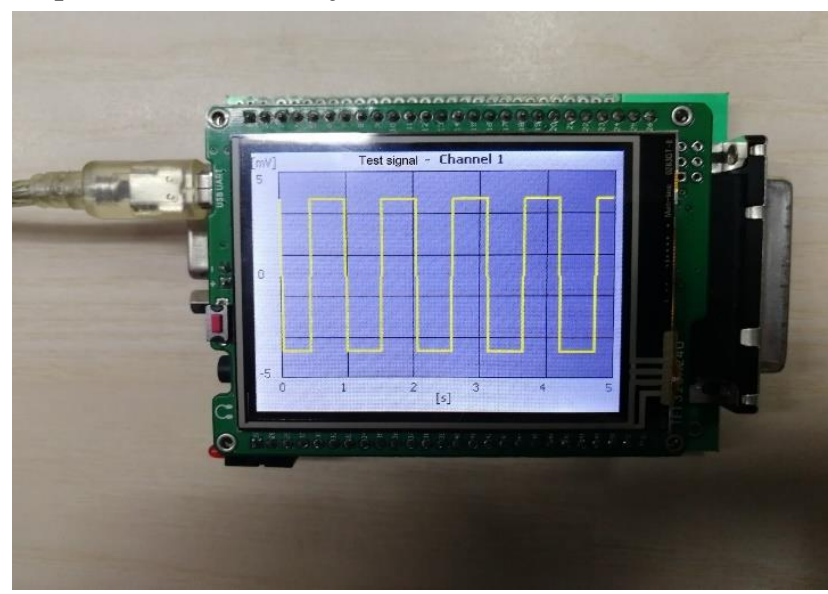

Slika 2. Test signal

\subsection{Elektrofiziološki signali}

Prilikom testiranja rada uređaja snimljena su dva tipa elektrofizioloških signala: EMG i EKG signal.

Za snimanje EMG signala korišćena je bipolarna konfiguracija elektroda (pozitivna, negativna i DRL elektroda) postavljena na flexor carpi ulnaris mišiću. Frekvencija odabiranja uređaja je podešena na $500 \mathrm{~Hz}$. Razlog tome je veći frekvencijskog opseg koji obuhvata sam EMG signal (najznačajnije frekvencije se nalaze u opsegu od oko 50 do oko $150 \mathrm{~Hz}$ ). Filtrirani EMG signal sniman na vremenskom intervalu od 0 do 10 sekundi i sa amplituskom rezolucijom od +/- $1 \mathrm{mV}$ prikazan je na slici 3 .

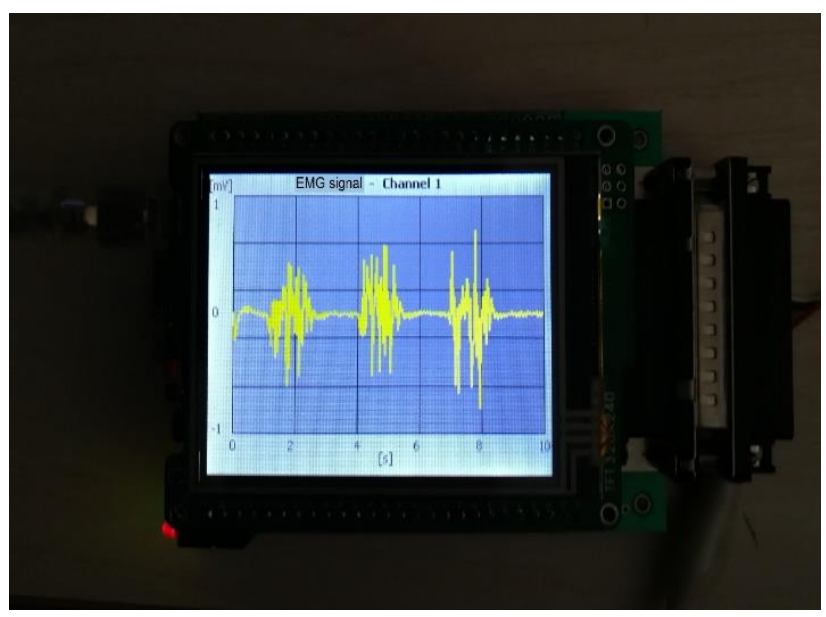

Slika 3. EMG signal

Za snimanje EKG signala korišćen je prvi bipolarni odvod. Pozitivna elektroda je postavljena na desnu ruku, dok su negativna i DRL elektroda postavljene na levu ruku. Frekvencija odabiranja je podešena na $250 \mathrm{~Hz}$. Razlog tome je niži frekvencijskog opseg koji obuhvata sam EKG signal. Filtrirani EKG signal sniman na vremenskom intervalu od 0 do 5 sekundi i sa amplitudskom rezolucijom od $+/-1 \mathrm{mV}$ prikazan je na slici 4 . 


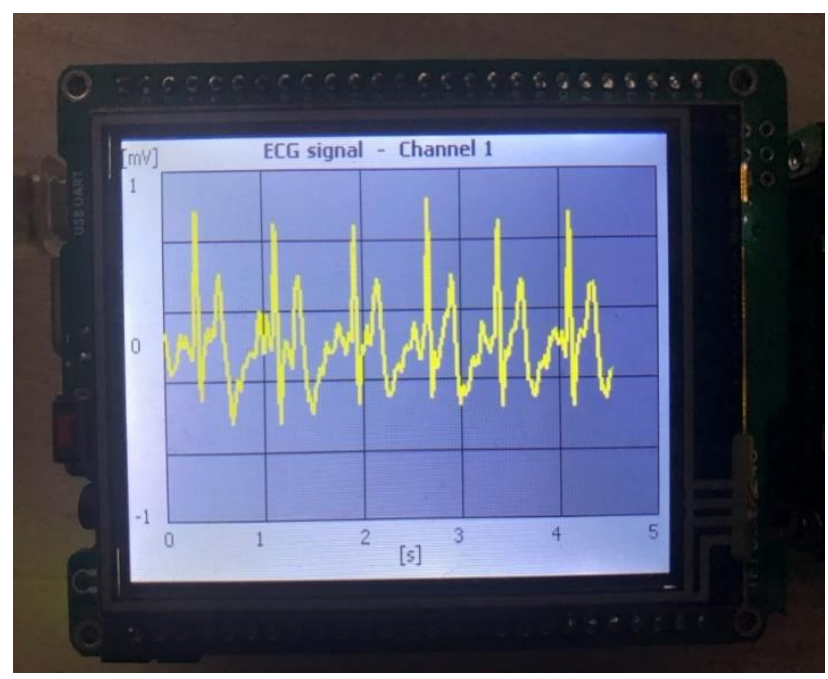

Slika 4. EKG signal

\section{ZAKLJUČAK}

Realizovani edukativni elektrofiziološki akvizicioni uređaj zasnovan na Mikromedia for XMEGA razvojnoj pločici i integrisanom kolu ADS1299 omogućava korisni$\mathrm{ku}$, pre svega studentima, da vrše merenja elektrofizioloških signala tokom izvođenja laboratorijskih vežbi i pritom steknu praktično znanje iz oblasti elektrofiziologije i merno-akvizicionih sistema. Uređaj je jednostavan za upotrebu, prenosiv, a odlikuje ga stabilnost u radu.

$\mathrm{U}$ radu su detaljno opisane hardverske komponente koji čine ovaj uređaj, kao i firmver koji se izvršava na mikrokontroleru Atxmega128A1. Posebna pažnja posvećena je procesu akvizicije samih signala.

Uzimajući u obzir elektrofiziološke akvizicione sisteme opisane u uvodu ovog rada, performanse realizovanog uređaja se mogu poboljšati implementacijom merenja impedanse interfejsa elektroda-tkivo na samom mikrokontroleru. Konačno, uređaj bi bio potpun kada bi se isprogramirao i modul za pulsnu oksimetriju, što bi obezbedilo i mogućnost merenja nivoa oksigenisanosti krvi u organizmu.

\section{LITERATURA}

[1] D. Popović, M. Popović, ,Biomedicinska merenja i instrumentacija“, Akademska misao, Beograd 2007.

[2] O. Tomašević, L. Mejić, D. Stanišić, V. Ilić, F. Gašparić, „A Portable Device for Physiological Measurements in Biomedical Engineering Education", Serbian Journal of Electrical Engineering, Vol. 16, No.1, 55-77, 2019.

[3] R. Stojanović, D. Karadaglić, „An Economical and Feasible Teaching Tool for Biomedical Education", Proceedings of the 24th International Symposium on Computer-Based Medical Systems (CBMS), Bristol, Ujedinjeno Kraljevstvo, 2011.

[4] A. Hafid, S. Benouar, M. Kedir-Talha, F. Abtahi, M. Attari, F. Seoane, ,F Full Impedance Cardiography Measurement Device Using Raspberry Pi3 and System-on-Chip Biomedical Instrumentation Solutions", IEEE Journal of Biomedical and Health Informatics, Vol. 22, No. 6, 1883-1894, 2018.
[5] C. A. Valliappan, A. Balaji, S. R. Thandayam, P. Dhingra, V. Baths, ,A Portable Real Time ECG Device for Arrhythmia Detection Using Raspberry $P i^{*}$, Proceedings of the 6th International Conference on Wireless Mobile Communication and Healthcare (MobiHealth 2016), Italija, 2016.

[6] T. Cruz, S. Brás, S. C. Soares, J. M. Fernandes, „Monitoring Physiology and Behavior Using Android in Phobias", Proceedings of the 37th International Conference of the IEEE Engineering in Medicine and Biology Society (EMBC), Italija, 2015.

[7] ,Mikromedia for XMEGA Manual““, Ver. 1.11, MikroElektronika, 2012.

[8] ,8-bit Atmel XMEGA A Microcontroller XMEGA“, A MANUAL 8077I-AVR 11/2012, Atmel.

[9] ,ADS1299-x Low-Noise, 4-, 6-, 8-Channel, 24-Bit, Analog-to-Digital Converter for EEG and Biopotential Measurements, ADS1299, ADS1299-4, ADS1299-6“, Texas Instruments, SBAS499C, 2017.

[10] N. Jorgovanović, M. Stanković, Ž. Tepić, V. Ilić, D. Bojanić, ,Laboratory System for Physiological Measurements", Proceedings of the 1st International Conference on Electrical, Electronic and Computing Engineering, IcETRAN, Srbija, 2014.

\section{Kratka biografija:}

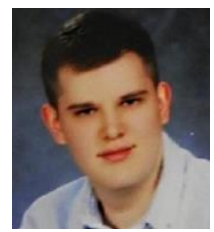

Boris Knežević rođen je u Subotici 1995. god. Master rad na Fakultetu tehničkih nauka iz oblasti Elektrotehnike i računarstva Biomedicinsko inženjerstvo odbranio je 2019. god.

kontakt: borisknezevic@uns.ac.rs 